\title{
MULTIVARIATE CONTROL CHARTS BASED ON DATA DEPTH FOR SUBGROUP LOCATION AND SCALE - CASE STUDY

\author{
Izabela D. Czabak-Górska ${ }^{1}$
}

\begin{abstract}
The purpose of the article is to present a method for determining control charts, which allow to control few interrelated quality characteristics. Often, in production practice, there is a need to simultaneously control several interrelated quality characteristics. The use of univariate control charts, separately for each quality characteristics, may lead to inadequate corrective actions of a production process. In such situations, it is recommended to use multivariate control charts, for example, the T2 control chart. However, the use of this classic approach involves making complicated calculations. Therefore, the author of this paper suggests using multivariate control charts based on data depth proposed by Liu. In this paper, the author presented the idea and principles of the multivariate control chart based on data depth and then, using it to assess the statistical stability of the process in a manufacturing company, engaged in the production of window fittings.
\end{abstract}

UDC Classification: 338.3; DOI: http://dx.doi.org/10.12955/cbup.v6.1292

Keywords: $Q$ Control Chart, multivariate control chart, Mahalanobis depth, depth function

\section{Introduction}

Control charts proposed in 1924 by Walter A. Shewhart, are one of the most basic and effective tools for quality control. Control charts are used to identify non-random behaviors of the tested production process by monitoring the changes in the distribution of the tested quality characteristics of the product. The most popular univariate charts are: Individual (XI) control chart, Mean and Range $\left(\mathrm{X}^{-}-\mathrm{R}\right)$ control chart, Cumulative Sum (CUSUM) control chart.

Often, in production practices, there is a need to monitor and control two or more Key Product Characteristics (KPC) at the same time. Therefore, an independent control of KPC when using a univariate control chart can lead to an erroneous evaluation of the statistical regulation of the process. According to Montgomery (2009), this is due to the fact that both Type I error, i.e., recognition that the process is out-of-control in the case of its in-control, as well as the probability of occurrence of observations within the control limits are not the same as in the case the univariate control chart. In such cases, it is suggested to use a multivariate control chart such as: Hotelling T2 control chart, Generalized Variance Control Chart (GV) control chart, Multivariate Cumulative Sum (MCUSUM) control chart, or Multivariate Exponentially Weighted Moving Average (MEWMA) control chart. The above-mentioned methods are based, however, on the assumption of a normal or close-to-normal nature of the examined KPC, which in practice may be difficult to determine.

The aim of the article is to use nonparametric, multivariate control charts based on Mahalanobis data depth, to simultaneously keep track of two related KPCs monitored in the manufacturing process. The analysis was carried out in a manufacturing company that produces window fittings.

\section{Multivariate control charts - a brief review of literature}

Multivariate control charts are commonly used to simultaneously monitor many KPCs in order to detect variations in the production process based on changes in the average or spread. The classic Multivariate control charts are: Hotelling's proposed by Hotelling (1947), multivariate CUSUM developed by Crosier (1988) or multivariate EWMA by Lowry et al. (1992). Other authors who have been involved in multivariate control charts are, for example: Celano \& Castagolia (2014), who proposed a multivariate control chart to monitor the proportion between two components or elements in a product, Lowry \& Montgomery (1995), who carried out a comprehensive review of the literature in the field of multivariate control charts. These control charts are based on the assumption of multi-normality and the independence of measurement data, which in practice turns out to be difficult to meet.

According to Chen et al. (2016), although multivariate SPC has been extensively studied in the literature, it is still a challenge to implement multivariate control charts in the case when the distribution of measurement data of the studied KPCs are unknown. The authors propose a non-parametric approach when a small reference sample is given, and the control limits are determined on-line rather than fixed before monitoring. Qiu \& Hawkins (2001) proposed a non-parametric CUSUM chart based on antiranks, which, however, requires a large reference sample. In turn, Li et al. (2017), propose a control

\footnotetext{
${ }^{1}$ Faculty of Production and Logistics Engineering, Department of Production and Services Quality Engineering, Poland, i.czabak-gorska@po.opole.pl
} 
chart, using a spatial rank and a VS-MEWMA control chart, to reduce the amount of data from the process control state, due to which the use of a simulation (when in-control process state distribution parameters are unknown), to define control boundaries is not required.

Due to the assumptions and limitations of the above-mentioned multivariate control charts, the author decided to use the one Q proposed by Liu (1995) and discussed this in more detail in the next chapter.

\section{Mahalanobis data depth in the construction of control charts for subgrouped data}

A multivariate control chart, based on Mahalanobis data depth, was proposed by Liu (1995). The idea of this control chart is primarily to reduce multivariate qualitative measurements to a univariate index, determined by rank statistics called the depth measure. According to Liu, Parelius and Singh (1999), the depth measure is a way of evaluating the square distance of a given point $x \in \mathbb{R}^{k}$ (where $k \geq 1$ - the number of KPCs tested) or a sample $\left\{X_{1}, X_{2}, \ldots, X_{m}\right\}$ with respect to the average continuous probability distribution F (in-control process). Liu and Shingh (1993) emphasize that these types of charts simultaneously detect changes in position and variability. What is more, according to Kobylińska (2014), the undoubted advantage of these charts based on the depth measure is the fact that they do not require an assumption regarding the compatibility of the process distribution with the normal distribution or linear relationship between the analyzed KPC, such as in the case of the Hotelling $\mathrm{T}^{2}$ chart.

Liu, Parelius and Singh (1999) describe the following depth measures: Mahalanobis depth, half-space depth, convex hull peeling depth, Oja depth, simplicity depth, majority depth and likelihood depth. For the purposes of calculations in the case study, the author limited herself to discussing Mahalanobis depth, in case when the probability distribution is unknown and only the measurements from this distribution are given (an empirical case).

Mahalanobis depth, according to the work of-Hamurkaroglu, Mert and Saykan (2004), for $\bar{X}$ constituting a random vector from the distribution $F$ and $R^{k}$ and for any point $x$ in $R^{k}$ relative to the distribution $F$, is expressed by the following relationship:

$$
M D\left(F_{m}, x\right)=\frac{1}{\left[1+(\boldsymbol{x}-\overline{\boldsymbol{X}})^{\prime} \boldsymbol{S}^{-\mathbf{1}}(\boldsymbol{x}-\overline{\boldsymbol{X}})\right]^{\prime}}
$$

where:

$\boldsymbol{x}-$ KPC observation vector with the dimension of $k \times 1$,

$\overline{\boldsymbol{X}}$ - sample vector medium with the dimension of $k \times 1$,

$\boldsymbol{S}^{\mathbf{- 1}}$ - matrix that is inverse to the covariance matrix with the dimension of $k \times k$.

Liu, Singh and Teng (2004) argue that using the depth measure provides center-outward ordering of data points within a given sample. A lower value $M D\left(F_{m}, x\right)$ for $X$ in $R^{k}$ means greater distance from the average distribution $\mathrm{F}$, and higher value $M D\left(F_{m}, x\right)$ for $X$ in $R^{k}$ means a smaller distance from the average distribution of F. Other properties of the depth measure were discussed by Hamurkaroglu, Mert and Saykan (2004) and Zou and Serfling (2000).

Let $F$ and $G$ be distribution functions of two independent $k$-dimensional populations. In turn $\left\{X_{1}, X_{2}, \ldots, X_{m}\right\}$ is an $n$-elemental sample taken from population $F$, which is referred to as a reference sample of the control process. Whereas $\left\{Y_{1}, Y_{2}, \ldots, Y_{p}\right\}$ is the new $n$-element sample from the manufacturing process with a G-distribution. Checking whether the process is controllable or whether the deterioration of the product's quality took place consists in a comparison of the distribution $F$ and $G$ using observation $\left\{Y_{1}, Y_{2}, \ldots, Y_{p}\right\}$ and assesement of the depth measure relative to the distribution $F$. In a situation where $\left\{Y_{1}, Y_{2}, \ldots, Y_{p}\right\}$ is more distant from the distribution $F$ it should be recognized that the process has shifted or there has been a change in the variability of the distribution. In short, to assess whether a process is controllable, the following null hypothesis should be verified against an alternative hypothesis:

$$
H_{0}: F=G
$$

$$
H_{1} \text { : changing of mean and increase of level of variation with respect to distribution } F^{*}
$$

Relative rank statistics specifying the depth of point $Y_{i}$ in $R^{k}$ from a set of observations $\left\{Y_{1}, Y_{2}, \ldots, Y_{p}\right\}$ in relation to a given theoretical distribution $\mathrm{F}$, when $X \sim F$ and $Y \sim G$ and data based on the extent of depth is an expression of: 
where:

$$
r_{M D}\left(F_{m}, Y_{i}\right)=\#\left\{M D\left(F_{m}, X_{j}\right) \leq M D\left(F_{m}, Y_{i}\right), j=1,2, \ldots, m\right\} / m
$$

$\#\{\cdot\}$-size of the set under consideration,

$m$ - number of observations,

$M D\left(F_{m} ; X\right)$ - Mahalanobis depth measure for sample $\left\{X_{1}, X_{2}, \ldots, X_{m}\right\}$ relative to the distribution $F$.

$M D\left(F_{m} ; Y\right)$ - Mahalanobis depth measure for sample $\left\{Y_{1}, Y_{2}, \ldots, Y_{p}\right\}$ relative to the distribution $F$.

According to the work of Liu (1995) discussed in this article, multivariate chart $Q$ is the equivalent of an average univariate chart $\bar{X}$, in which the test statistic is the sample average $r_{M D}\left(F_{m}, Y_{i}\right)$ :

where:

$$
Q\left(F_{m}, G_{p}^{j}\right)=\frac{1}{n} \sum_{i=1}^{n} r_{M D}\left(F_{m}, Y_{i}\right)
$$

$j$ - subset number (observation),

$G_{p}^{j}$ - empirical distribution $Y_{i}$ inj-th subset (of observation).

Hamurkaroglu, Mert and Saykan (2004) defined a zero and an alternative hypothesis as:

$$
\begin{gathered}
H_{0}: F=G, Q\left(F_{m}, G_{p}^{j}\right)=\frac{1}{2} \\
H_{1}: Q\left(F_{m}, G_{p}^{j}\right)<\frac{1}{2} p
\end{gathered}
$$

which means that if an alternative hypothesis is adopted, on average more than $50 \%$ of the population examined from the distribution $F$ is deeper (more centrally) than any observation $Y_{i}$ from the distribution $G$. Consequently, the control limits for a small sample $(n<5)$ can be determined based on:

$$
\begin{gathered}
U L C=\text { lack } \\
C L=0.5 \\
L C L=\frac{(n ! \alpha)^{1 / n}}{n}
\end{gathered}
$$

where:

$n$ - number of w elements in the observation,

$\alpha$-acceptable probability of false alarm (in production practices, $\alpha \leq 0.0027$ is applied).

More detailed information, as well as justification for determining control limits using the dependence (6) for chart $Q$ can be found in the study of Liu and Singh (1993).

\section{Case of study}

The research was carried out in a manufacturing enterprise in the Opolskie voivodship (Poland), dealing in the production of window fittings. The end of an espagnolette was tested using a control chart $Q$. This is the fitting element responsible for the functionality, and more specifically the clamping of the window sash to the frame (Fig. 1).

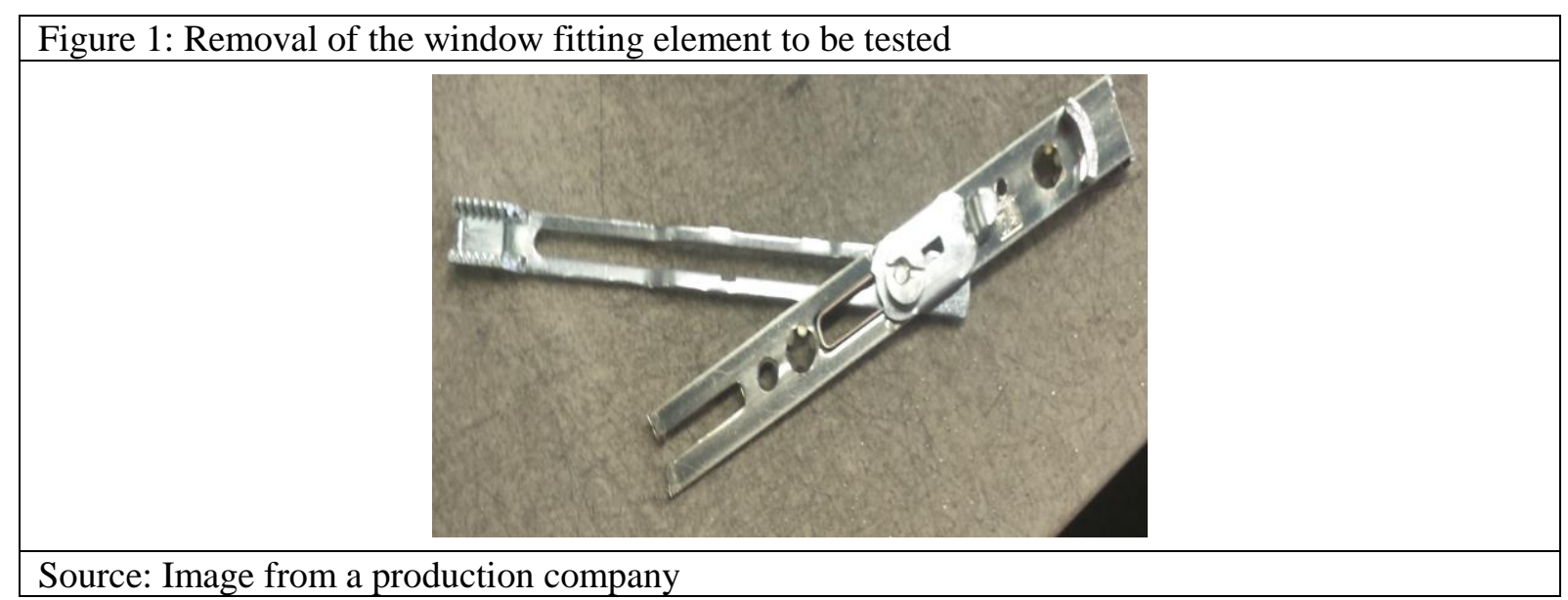

The manufacturing process of the tested element is reduced to the following operations (Figure 2):

1. Riveting of bearing diverticulum, steady bar and centering element.

2. Assembly of a spring. 
3. Riveting of a locking bolt, stabilizing element and an element made after operations 1-2 in a zero position.

4. Embedding and riveting of a decorative casing.

Riveting of a guiding element and an element made in operations 1-4.

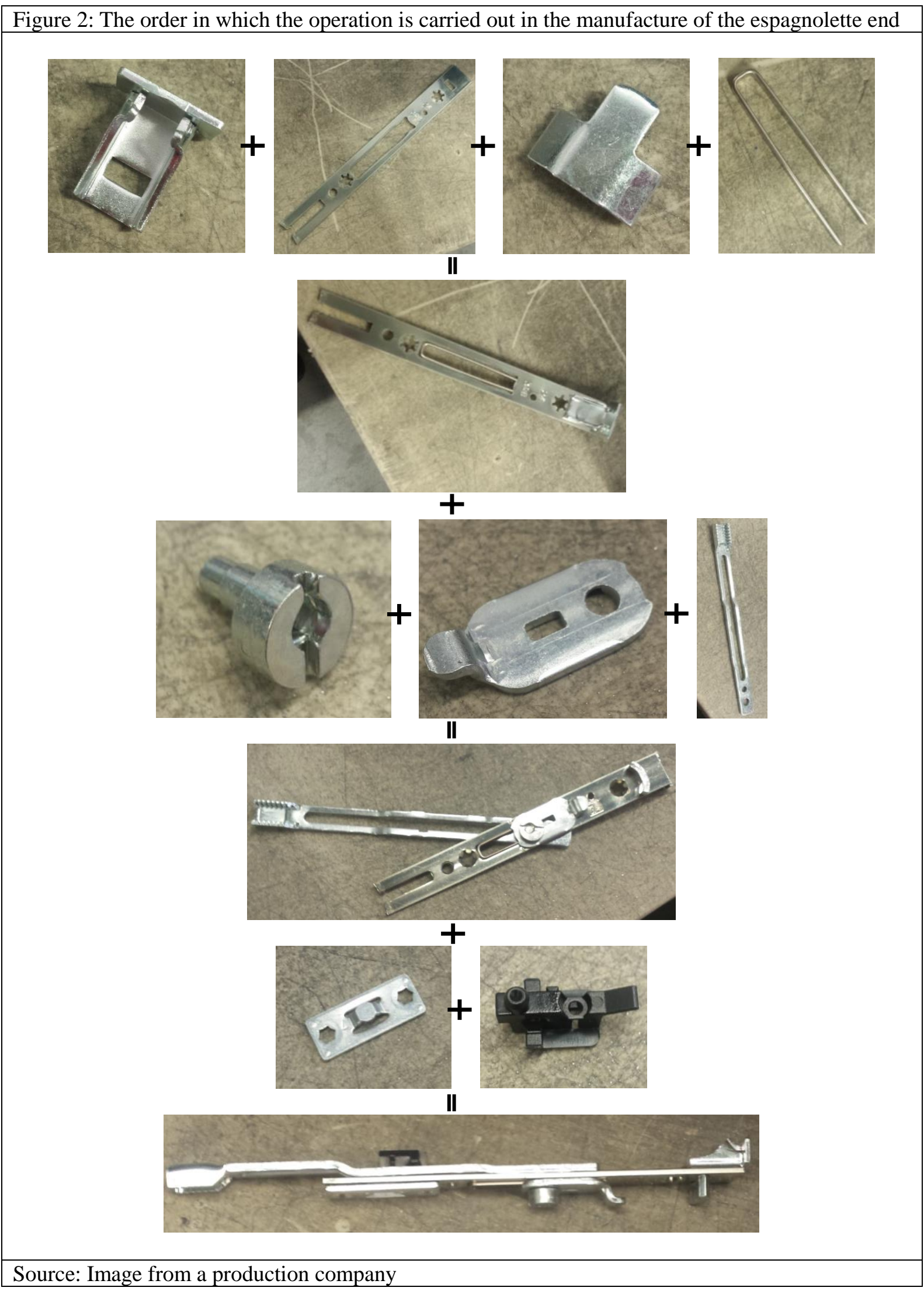



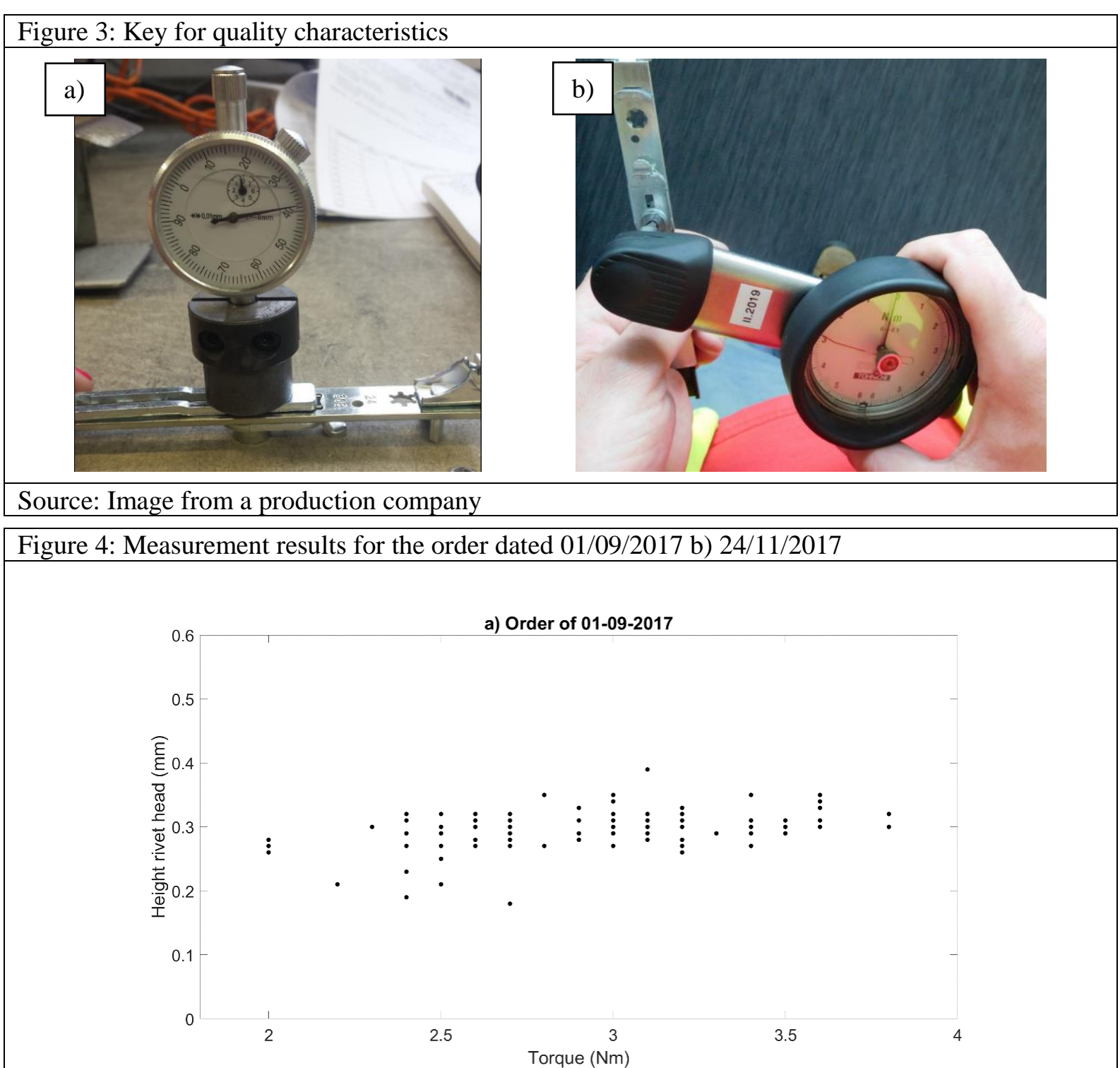

b) Order of 24-10-2017

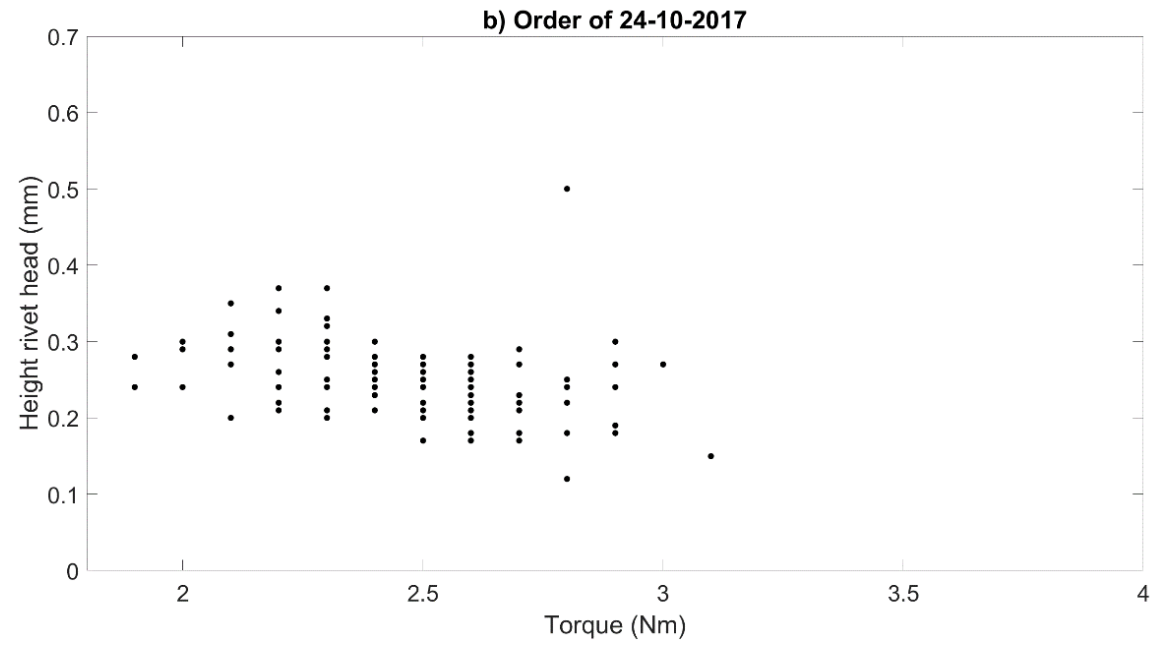

Source: Author

The key features for quality, interrelated and subject to control are:

- The height of rivet head (control after operation 3), whose height should not exceed $0.3 \mathrm{~mm}$ (Fig. $3 a)$ - the control and measurement device used to perform measurements is an altimeter with an accuracy of $0.01 \mathrm{~mm}$, 
The torque on the bolt (control after operation 3), which should be in the range of 2.0-4.0 Nm (Fig. 3b) - the control and measurement device used to perform the measurements is a torque wrench with an accuracy of $0.01 \mathrm{~mm}$.

A torque which is too low will result in insufficient clamping of the window sash to the frame, as well as the window's self-adjustment. The height of the rivet's head is influenced by the setting of the riveting machine (including riveting time, stroke, pressure, shape of the riveting tool's mandrel) as well as the quality of the rivet itself. In addition, it is known that the lower the height of the rivet head, the higher the torque.

The analysis covered 3-piece samples from two different orders dated 01/09/2017 and 24/10/2017 (Fig. 4), which were collected in accordance with internal procedures (a total of 40 measurements for each of the examined KPCs). Between the orders, the machines were retooled, and other products were manufactured at that time.

In Table. 1, the values of the Mahalanobis depth measure for the measurement data from the order dated 01/09/2017 are presented, determined on the basis of dependence (1) separately for each measurement. On the other hand, in Table. 2, the values of the Mahalanobis depth measure for the measurement data from the order of 24/10/2017 and the relative rank statistics based on the dependence (1) and (2) for each measurement are listed.

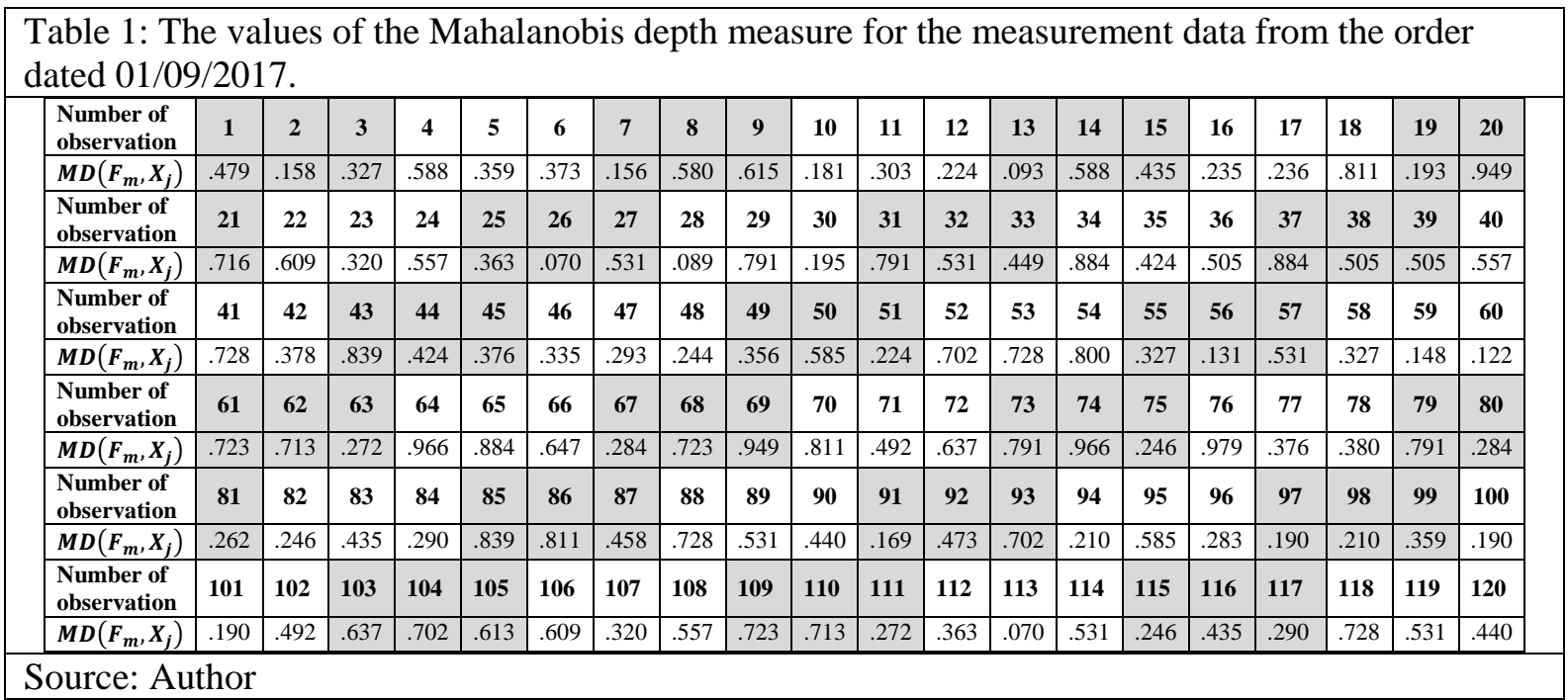

Table 2: The values of the Mahalanobis depth and the relative rank statistic for the measurement data from the order of 24/10/2017

\begin{tabular}{|c|c|c|c|c|c|c|c|c|c|c|c|c|c|c|c|c|c|c|c|c|}
\hline $\begin{array}{l}\text { Number of } \\
\text { observation }\end{array}$ & 1 & 2 & 3 & 4 & 5 & 6 & 7 & 8 & 9 & 10 & 11 & 12 & 13 & 14 & 15 & 16 & 17 & 18 & 19 & 20 \\
\hline$M D\left(F_{m}, Y_{i}\right)$ & .132 & .129 & .096 & .283 & .060 & .224 & .072 & .067 & .123 & .224 & .136 & .180 & .129 & .204 & .129 & .256 & .166 & .123 & .279 & .256 \\
\hline$r_{M D}\left(F_{m}, Y_{i}\right)$ & .050 & .042 & .033 & .242 & .000 & .158 & .017 & .000 & .042 & .158 & .050 & .083 & .042 & .133 & .042 & .217 & .075 & .042 & .242 & .217 \\
\hline $\begin{array}{l}\text { Number of } \\
\text { observation }\end{array}$ & 21 & 22 & 23 & 24 & 25 & 26 & 27 & 28 & 29 & 30 & 31 & 32 & 33 & 34 & 35 & 36 & 37 & 38 & 39 & 40 \\
\hline$M D\left(F_{m}, Y_{i}\right)$ & .136 & .159 & .320 & .440 & .059 & .070 & .072 & .162 & .029 & .531 & .345 & .440 & .237 & .266 & .105 & .125 & .345 & .922 & .557 & .531 \\
\hline$r_{M D}\left(F_{m}, Y_{i}\right)$ & .050 & .075 & .317 & .497 & .000 & .017 & .017 & .075 & .000 & .617 & .350 & .475 & .183 & .225 & .033 & .042 & .350 & .958 & .642 & .617 \\
\hline $\begin{array}{l}\text { Number of } \\
\text { observation }\end{array}$ & 41 & 42 & 43 & 44 & 45 & 46 & 47 & 48 & 49 & 50 & 51 & 52 & 53 & 54 & 55 & 56 & 57 & 58 & 59 & 60 \\
\hline$M D\left(F_{m}, Y_{i}\right)$ & .059 & .107 & .063 & .067 & .061 & .320 & .063 & .107 & .162 & .202 & .157 & .037 & .127 & .075 & .531 & .129 & .609 & .150 & .256 & .266 \\
\hline$r_{M D}\left(\boldsymbol{F}_{m}, \boldsymbol{Y}_{i}\right)$ & .000 & .033 & .000 & .000 & .000 & .317 & .000 & .033 & .075 & .133 & .067 & .000 & .042 & .017 & .617 & .042 & .700 & .058 & .217 & .225 \\
\hline $\begin{array}{l}\text { Number of } \\
\text { observation }\end{array}$ & 61 & 62 & 63 & 64 & 65 & 66 & 67 & 68 & 69 & 70 & 71 & 72 & 73 & 74 & 75 & 76 & 77 & 78 & 79 & 80 \\
\hline$M D\left(F_{m}, Y_{i}\right)$ & .180 & .106 & .131 & .387 & .455 & .128 & .122 & .129 & .579 & .237 & .440 & .130 & .387 & .266 & .356 & .161 & .249 & .206 & .189 & .237 \\
\hline$r_{M D}\left(F_{m}, Y_{i}\right)$ & .083 & .033 & .050 & .433 & .500 & .042 & .042 & .042 & .650 & .183 & .475 & .042 & .433 & .225 & .358 & .075 & .217 & .133 & .092 & 0.183 \\
\hline $\begin{array}{l}\text { Number of } \\
\text { observation }\end{array}$ & 81 & 82 & 83 & 84 & 85 & 86 & 87 & 88 & 89 & 90 & 91 & 92 & 93 & 94 & 95 & 96 & 97 & 98 & 99 & 100 \\
\hline$M D\left(F_{m}, Y_{i}\right)$ & .237 & .067 & .206 & .147 & .125 & .130 & .531 & .206 & .320 & .256 & .125 & .192 & .105 & .286 & .131 & .202 & .330 & .345 & .330 & .206 \\
\hline$r_{M D}\left(F_{m}, Y_{i}\right)$ & .183 & .000 & .133 & .050 & .042 & .042 & .617 & .133 & .317 & .217 & .042 & .117 & .033 & .267 & .050 & .133 & .342 & .350 & .342 & .133 \\
\hline $\begin{array}{l}\begin{array}{l}\text { Number of } \\
\text { observation }\end{array} \\
\end{array}$ & 101 & 102 & 103 & 104 & 105 & 106 & 107 & 108 & 109 & 110 & 111 & 112 & 113 & 114 & 115 & 116 & 117 & 118 & 119 & 120 \\
\hline$M D\left(F_{m}, Y_{i}\right)$ & .206 & .099 & .144 & .216 & .355 & .330 & .105 & .125 & .162 & .228 & .107 & .255 & .162 & .195 & .266 & .626 & .345 & .256 & .716 & .579 \\
\hline$r_{M D}\left(F_{m}, Y_{i}\right)$ & .000 & .033 & .050 & .150 & .350 & .342 & .033 & .042 & .075 & .167 & .033 & .217 & .075 & .133 & .225 & .717 & .350 & .217 & .792 & .650 \\
\hline
\end{tabular}


Then, according to the relationship (4), the test statistic was determined for chart $Q$ (sample average $r_{M D}\left(F_{m}, Y_{i}\right)$ - Tab. 3) and a control chart for $\alpha=0.0027$ (Fig.5) was made, for which the control limits have been determined based on equation (6), respectively: $C L=0.5, L C L=\frac{(3 ! \cdot 0.0027)^{1 / 3}}{3}=0.084$.

Table 3: The values of the sample mean relative rank statistics $Q\left(F_{m}, G_{p}^{j}\right)$ for the measurement data from the order of $24 / 10 / 2017$

\begin{tabular}{|l|c|c|c|c|c|c|c|c|c|c|c|c|c|c|c|c|c|c|c|c|}
\hline $\begin{array}{l}\text { Number of } \\
\text { observation }\end{array}$ & $\mathbf{1}$ & $\mathbf{2}$ & $\mathbf{3}$ & $\mathbf{4}$ & $\mathbf{5}$ & $\mathbf{6}$ & $\mathbf{7}$ & $\mathbf{8}$ & $\mathbf{9}$ & $\mathbf{1 0}$ & $\mathbf{1 1}$ & $\mathbf{1 2}$ & $\mathbf{1 3}$ & $\mathbf{1 4}$ & $\mathbf{1 5}$ & $\mathbf{1 6}$ & $\mathbf{1 7}$ & $\mathbf{1 8}$ & $\mathbf{1 9}$ & $\mathbf{2 0}$ \\
\hline $\boldsymbol{Q}\left(\boldsymbol{F}_{\boldsymbol{m}}, \boldsymbol{G}_{p}^{\boldsymbol{j}}\right)$ & .125 & .400 & .058 & .292 & .217 & .333 & .508 & .883 & .033 & .692 & 1.008 & .300 & 1.950 & .650 & .000 & .350 & .275 & .058 & 1.358 & .500 \\
\hline $\begin{array}{l}\text { Number of } \\
\text { observation }\end{array}$ & $\mathbf{2 1}$ & $\mathbf{2 2}$ & $\mathbf{2 3}$ & $\mathbf{2 4}$ & $\mathbf{2 5}$ & $\mathbf{2 6}$ & $\mathbf{2 7}$ & $\mathbf{2 8}$ & $\mathbf{2 9}$ & $\mathbf{3 0}$ & $\mathbf{3 1}$ & $\mathbf{3 2}$ & $\mathbf{3 3}$ & $\mathbf{3 4}$ & $\mathbf{3 5}$ & $\mathbf{3 6}$ & $\mathbf{3 7}$ & $\mathbf{3 8}$ & $\mathbf{3 9}$ & $\mathbf{4 0}$ \\
\hline $\boldsymbol{Q}\left(\boldsymbol{F}_{\boldsymbol{m}}, \boldsymbol{G}_{\boldsymbol{p}}^{\boldsymbol{j}}\right)$ & .167 & .975 & .733 & .700 & 1.017 & .425 & .458 & .183 & .700 & .667 & .192 & .450 & 1.033 & .167 & .550 & .417 & .275 & .425 & 1.292 & 1.658 \\
\hline
\end{tabular}

Source: Author

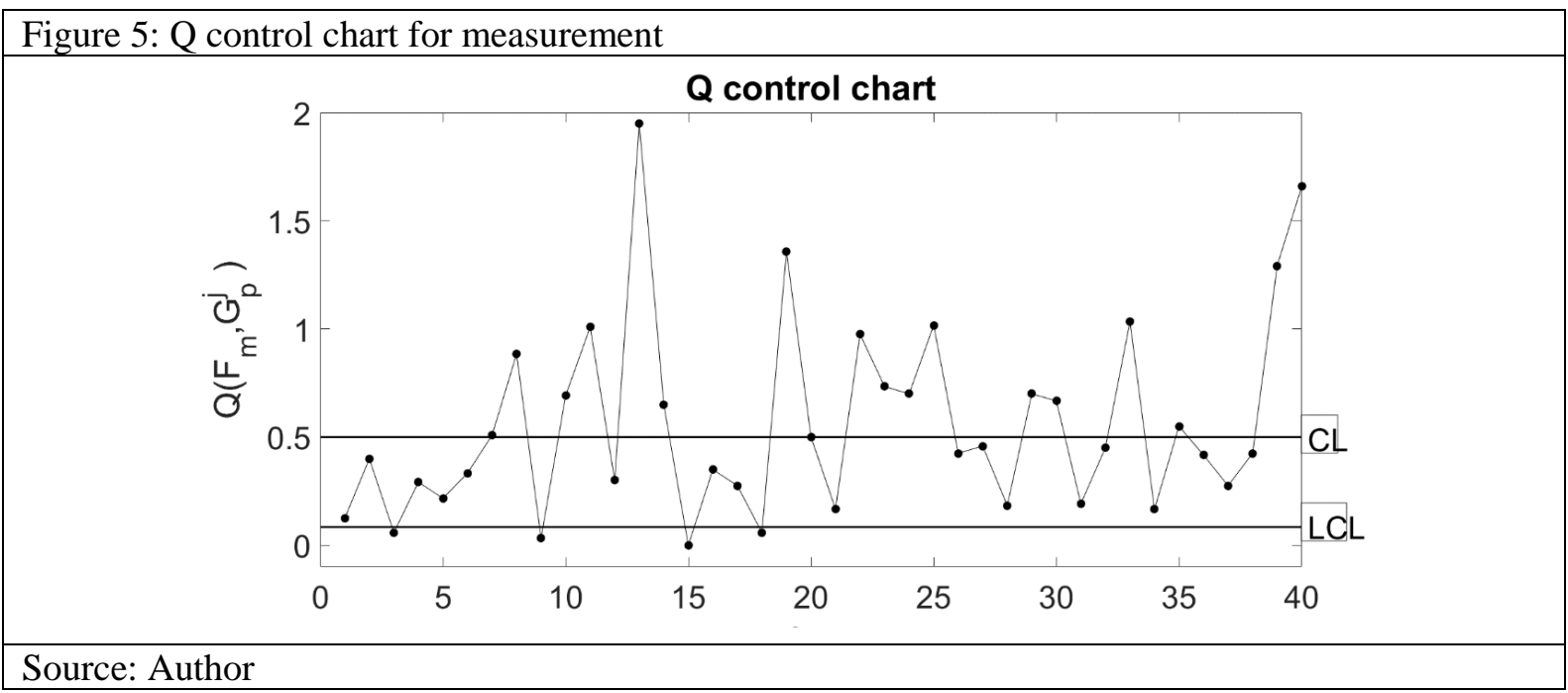

Analyzing Fig. 5, it can be clearly seen that four points exceed the lower control limit, which may suggest a shift in the mean value. Additionally, the sample averages of the analyzed rank statistics $Q\left(F_{m}, G_{p}^{j}\right)$ show large "jumps" of the value, which may be another proof of changes in the production process in the field of distribution (some measurements are deeply immersed in the reference schedule - points above the central control limit, and others much shallower - points near the lower control limit). Additional analyses carried out in the production company to explain the situation indicate that first of all, unambiguous procedures should be introduced for machine parameter setters that rivet components of the product under analysis - it has been ensured that the values of the tested KPCs are within the tolerance limits, which was caused because at one time the measurements were closer to the lower range and sometimes they were closer to the upper tolerance range, which simultaneously affects the stability of the production process.

\section{Conclusion}

The article presents a method for determining control charts based on Mahalanobis data depth. The presented approach makes it possible to transform multivariate measurements of the KPC investigated from the production process into univariate indicators of rank statistics. $r_{M D}\left(F_{m}, Y_{i}\right)$. Presented control chart $Q$ allows simultaneous monitoring of the average value shift and change of distribution in the examined process without preliminary assumptions such as multi-normality, autocorrelation or linear relationship of the examined KPC.

The graph from Fig. 5 indicates a change in the distribution of measurements before and after conversion of machines, both in relative changes of position and dispersion, which means that it is necessary to take corrective actions or improve the production process. In addition, the case study presented in this article allows to determine whether a change in the manufacturing process takes place during a changeover of the machine. An undoubted disadvantage of this type of approach is the fact that it was not clearly stated if the reference distribution prior to the changeover is the in-control state of the production process (Phase II of the implementation of control charts). In short, the solution to the reference distribution, 
which will represent the in-control state of the studied production process remains an issue to be clarified (Phase I of implementation of control charts). The solution to this problem may be (2014) a control chart proposed by Li et al. dedicated to the Phase I implementation of control charts, whose determination of control boundaries is also based on Mahalanobis data depth, which will be the subject of further research by the author.

\section{References}

Celano, G., \& Castagliola, P. (2016). Design of a phase II control chart for monitoring the ratio of two normal variables. Quality and Reliability Engineering International, 32(1), 291-308.

Chen, N., Zi, X., \& Zou, C. (2016). A distribution-free multivariate control chart. Technometrics, 58(4), 448-459.

Crosier R.B. (1988). Multivariate Generations of Cumulative Sum Quality control Schemes. Technometrics 30: 219-303.

Hamurkaroglu, C., Mert, M., \& Saykan, Y. (2006). Nonparametric control charts based on Mahalanobis depth. Quality Control and Applied Statistics, 51(1), 21.

Hotelling H. (1947). Multivariate Quality Control-Illustrated by the Air Testing of Sample Bombsights. in: Eisenhart, C. Hastay, M. W., and Wallis, W. A. (eds.). Tech. Stat. An. McGraw-Hill, New York, NY. 111-184.

Kobylińska, M. (2012). Wykorzystanie zanurzania obserwacji w próbie do konstrukcji kart kontrolnych. Metody Ilościowe w Badaniach Ekonomicznych, 13(3), 127-136.

Li, W., Pu, X., Tsung, F., \& Xiang, D. (2017). A robust self-starting spatial rank multivariate EWMA chart based on forward variable selection. Computers \& Industrial Engineering, 103, 116-130.

Li, Z., Dai, Y., \& Wang, Z. (2014). Multivariate change point control chart based on data depth for phase I analysis. Communications in Statistics-Simulation and Computation, 43(6), 1490-1507.

Liu, R. Y. (1995). Control charts for multivariate processes. Journal of the American Statistical Association, 90(432), 13801387.

Liu, R. Y., \& Singh, K. (1993). A quality index based on data depth and multivariate rank tests. Journal of the American Statistical Association, 88(421), 252-260.

Liu, R. Y., Parelius, J. M., \& Singh, K. (1999). Multivariate analysis by data depth: descriptive statistics, graphics and inference (with discussion and a rejoinder by Liu and Singh). The annals of statistics, 27(3), 783-858.

Liu, R. Y., Singh, K., \& Teng, J. H. (2004). DDMA-charts: nonparametric multivariate moving average control charts based on data depth. Allgemeines Statistisches Archiv, 88(2), 235-258.

Lowry C.A., Woodall W.H., Champ C.W., Rigdon S.E. (1992). A Multivariate Exponentially Weighted Moving Average Control Chart. Technometrics 34 (1): 46-53.

Lowry, C. A., \& Montgomery, D. C. (1995). A review of multivariate control charts. IIE transactions, 27(6), 800-810.

Montgomery, D. C. (2009). Introduction to statistical quality control. 6th Edition, USA: John Wiley \& Sons, Inc.

Qiu P., Hawkins D.M. (2001). A rank based multivariate CUSUM procedure. Technometrics 43: 120-132.

Zuo, Y., \& Serfling, R. (2000). Structural properties and convergence results for contours of sample statistical depth functions. Annals of Statistics, 483-499. 